C. A. Crampton.-The suggestion seems to be a good one. I have no doubt it would dissolve less glucose.

In reply to $\mathrm{Mr}$. Elworthy, who stated that butter was now preserved in India on a large scale by the addition of salt only, in hermetically sealed cans, and kept for six or seven months, and who asked whether the figures given were for dry glucose, Mr. Crampton said that the glucose was calculated on the supposition that the same kind of glucose, "confectioners' sirup." had been used in all cases.

\title{
A METHOD FOR DETERMINING THE RESISTANCE OF ELECTROLYTES.
}

By Parker C. McILhiNex. Received January to, 1898

7 HE method commonly used for determining the resistance of an electrolyte is that of Kohlrausch, in which the resistance to be measured is made one arm of a Wheatstone bridge, while the current is an alternating one supplied by an induction coil and the balance is determined by a sensitive telephone instead of the galvanometer used in ordinary measurements. It is a zero method capable of a high degree of accuracy, but it is not very rapid and readings can not be taken at short intervals of time.

The method to be described does not lay claim to so high a degree of accuracy, as it is limited by errors in a galvanometer and by changes in the electromotive force of a battery during an experiment, but it is believed to have some advantages in the possibility of making many readings in a short space of time.

It consists briefly in determining by a galvanometer, preferably a d'Arsonval, the potential difference between the ends of a known resistance placed in series with the resistance to be determined. The current is supplied by a gravity battery and before passing through the electrolyte it is transformed into an alternating current by means of a rotary pole changer, but the current passing through the known resistance is direct.

When a current passes through two resistances in series the fall of potential in each of them is proportional to its resistance.

In Fig. I, let $R$ be a known resistance, $R^{\prime}$ be another known resistance, which may be replaced by the unknown resistance $X$. 
Let $f$ be the fall of potential in $\mathrm{R}$, when $\mathrm{R}^{\prime}$ is in series with it. Let $g$ be the fall of potential in $R$, when $X$ is in series with it. Let $\mathrm{E}$ be a constant electromotive force.

Then

$$
f=\frac{\mathrm{RE}}{\mathrm{R}+\mathrm{R}^{\prime}} \cdots \cdots \cdots \cdots \cdots \cdots \cdots(\mathrm{I})
$$

and

from which we get

$$
g=\frac{\mathrm{RE}}{\mathrm{R}+\mathrm{X}}
$$

$$
\mathrm{X}=\frac{(f-g) \mathrm{R}+f \mathrm{R}^{\prime}}{g}
$$

If we determine the fall of potential in $R$, when $R^{\prime}$, the other known resistance is in the series, then replace $R^{\prime}$ by $X$, the unknown resistance, and again determine the fall of potential, we shall be able, by substituting in (3), to determine the value of $X$. If $R$ be supposed equal to o equation (3) becomes

or

$$
\frac{f \mathrm{R}^{\prime}}{g}=X
$$

$g: f:: X: \mathbf{R}^{\prime}$

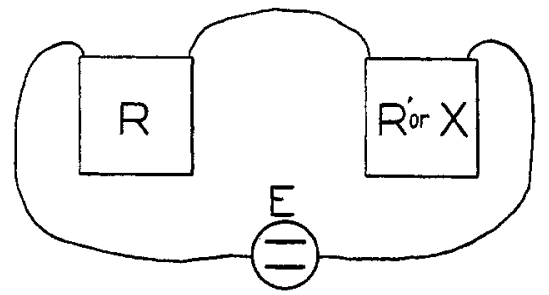

Fig. 1.

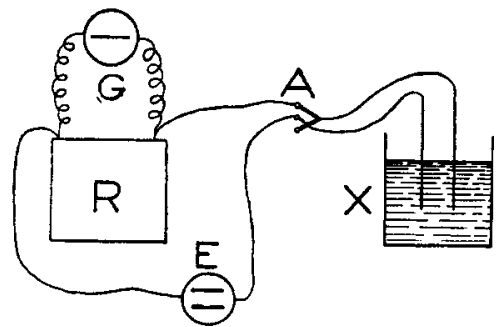

Fig.2.

If $R$ is very small in comparison with $R^{\prime}$, equation (5) may be assumed to be applicable without the introduction of serious 
error and the fall of potential in $R$ would then always be proportional to the conductivity of $R^{\prime}$.

If the measurement of the fall of potential in $R$ is made by a d'Arsonval galvanometer, which gives readings proportional to the electromotive force of the current passing through it, and $R$ is made small in proportion to $R^{\prime}$, the readings of the galvanometer give directly the conductivity of the electrolyte.

The method was devised to determine the resistance of silicates and similar substances under the influence of heat and for this purpose many readings had to be made. It proved well adapted to the purpose and probably would be convenient for other experiments in which a great many readings are desired from the same sample.

The apparatus necessary, aside from the containing vessel for the electrolyte and connecting wires, consists of two resistance boxes, one having small resistances, the other preferably containing resistances, of the same order of magnitude as the quantities to be determined, a d'Arsonval galvanometer and a rotary pole changer to convert the direct current from the battery into an alternating one, so as to prevent polarization. The pole changer is a simple machine driven very well by any small motor which gives a fairly regular rotation. The method of connecting the apparatus is shown in Fig. 2.

$\mathrm{R}$ is the small resistance box.

$\mathrm{X}$ is the electrolyte.

$\mathrm{E}$ is a gravity battery.

$A$ is the rotary pole changer.

$\mathrm{G}$ is the galvanometer.

The deflection of the galvanometer may be brought to a convenient figure for accurate reading, no matter what value $X$ may have, by altering the value of $R$. The resistance of the galvanometer must be known, in order to make the calculation. Part of the current coming to the terminals of $R$ passes through the galvanometer, and hence the resistance of the two together is slightly less than that of $\mathrm{R}$ alone. If we call the resistance of the galvanometer $\mathrm{S}$, then the resistance of $\mathrm{R}$ and $\mathrm{S}$ together $=$ $\frac{R S}{R+S}$. Here if $R$ is small enough in proportion to $S$ the con- 
ductivity of the galvanometer may be neglected, and if $R$ is changed to obtain a deflection more suitable for reading, the two readings may, without sensible error, be assumed proportional to the two values of $R$.

Changing $R$ of course changes the sensitiveness of the whole arrangement and this may be done to as great an extent as the coils in $\mathrm{R}$ will allow. If it contains coils of one-tenth to twenty ohms the sensitiveness may be varied two hundredfold by a change in plugs, an operation requiring only a few seconds. In the work on heated silicates the resistance varied with the temperature from a comparatively small figure to practical infuity and the method made its determination quite simple, particularly as the same galvanometer was used for determining conductivity and for determining temperature by the thermoelectric method. Alternate readings of temperature and conductivity were taken at intervals of some seconds during the cooling of the materials from a high temperature by the use of a suitably disposed double switch.

DEPARTMENT OF METALLURGY,

Columbia University, NEW York.

\section{THE COMMERCIAL ANALYSIS OF BAUXITE.}

By Wm. B. Phillips and David Hancock. Received January 5, 2898 .

THE bauxite mined in Georgia and Alabama, constituting manufacture of alum and aluminum, in the proportion of about three-fourths to one-fourth. The analytical methods hitherto employed have been based, to a considerable extent, upon the purposes to which the material was applied.

It is obvious that the easy solubility of the alumina in sulphuric acid is a great desideratum for the manufacturer of alum, and furthermore, that the acidulated mass should filter readily, and be capable of rapid washing.

But it is generally impracticable for the ordinary chemist to base his methods on factory tests, for the reason that these are, for the most part, unknown to him. All that can reasonably be required of him is that his methods should not yield results widely at variance with those obtained on a large scale in actual operations. 